\title{
ESTUDIOS EN LAS APOCYNACEAE NEOTROPICALES XIV: NUEVAS LECTOTIPIFICACIONES EN LOS GÉNEROS HYLAEA J.F. MORALES Y PENTALINON VOIGT (APOCYNOIDEAE, ECHITEAE)
}

\author{
J. Francisco Morales \\ Instituto Nacional de Biodiversidad, apdo. 22-3100, Santo Domingo, Heredia, Costa Rica
}

\begin{abstract}
Lectotypes are designated for the taxa Hylaea leptoloba (Monach.) J.F. Morales and Pentalinon andrieuxii (Müll. Arg.) B.F. Hansen \& Wunderlin (Apocynaceae, Apocynoideae, Echiteae).
\end{abstract}

Resumen. Se designan lectotipos para los taxa Hylaea leptoloba (Monach.) J.F. Morales y Pentalinon andrieuxii (Müll. Arg.) B.F. Hansen \& Wunderlin (Apocynaceae, Apocynoideae, Echiteae).

Palabras Clave / Key words: Apocynaceae, Apocynoideae, Echiteae, Hylaea, Pentalinon.

Debido a la pérdida del holotipo de Hylaea leptoloba (Monach.) J.F. Morales (Apocynaceae, Apocynoideae, Echiteae), se hace necesario designar un lectotipo, escogiendo entre el material original remanente. Asimismo, dado que dos sintipos fueron citados en la descripción de Urechites andrieuxii Müll. Arg. (Müller 1860) y ante la necesidad de designar un lectotipo para el proyecto Flora Mesoamericana, se procede a efectuar ambas lectotipificaciones.

Hylaea leptoloba (Monach.) J.F. Morales, Novon 9(1): 84. 1999. Prestonia leptoloba Monach., Phytologia 6: 12. 1957. TIPO. Brasil. Amazonas: Iraruca, Içana, 16 nov 1945 (fl), Fróes 21391. Holotipo: NY, perdido en 1978. Lectotipo (designado aquí): IAN, fotocopia y fotografía, INB.

El holotipo de esta especie se perdió en 1978, durante un envío de material del Herbario del New York Botanical Garden (NY) a Venezuela. Por tanto, se designa como lectotipo el único isotipo conocido.

Pentalinon andrieuxii (Müll. Arg.) B.F. Hansen \& Wunderlin, Taxon 35(1): 168. 1986. Urechites andrieuxii Müll. Arg., Linnaea 30: 442. 1860. TIPO: México. Oaxaca: cerca de Tehuantepec, ago 1834 (fl, fr), Andrieux 247. Lectotipo (designado aquí): GDC, foto F - neg. 26898 en INB; isolectotipo: P.

Dos sintipos fueron citados por Müller Argoviensis (1860) en la descripción de Urechites andrieuxii; el primero recolectado por Andrieux (247) cerca de Tehuantepec, en el estado de Oaxaca, México, y el segundo por Karwinsky (473) entre Tamatoc y Huejutla, Hidalgo, México. En la revisión monográfica del género Urechites (ahora un sinónimo de Pentalinon), Woodson (1936) no examinó ninguno de los dos sin- tipos, de manera que este taxon no fue lectotipificado. Posteriormente, Hansen \& Wunderlin (1986) demostraron que Pentalinon es un nombre más antiguo que Urechites; por tanto, transfirieron las especies del segundo al primero. Ellos hicieron las combinaciones necesarias, pero sólo efectuaron la lectotipificación de P. luteum (L.) B.F. Hansen \& Wunderlin. En el caso de $P$. andrieuxii, hicieron notar que un lectotipo debía ser escogido entre los sintipos citados por Müller (1860), dada su imposibilidad de examinar dichos especímenes.

Ahora bien, de los dos sintipos citados por Müller (1860) se designa como lectotipo el espécimen Andrieux 247 depositado en el herbario del Conservatoire et Jardin botaniques de Ginebra, Suiza (G). Esta decisión está sustentada en el hecho de que ese espécimen posee un duplicado adicional en el Herbario del Museo de Historia Natural de París (P), Francia, tiene tanto flores como frutos y, además, está documentado en la colección de fotografías de tipos del Field Museum of Natural History, Chicago. Además, el otro sintipo no pudo ser localizado; este ejemplar puede ser objeto de cierta controversia, dado que otro espécimen del mismo recolector posee el mismo número de recolecta (473) y es, a su vez, sintipo de otro taxon distinto: Mandevilla karwinskii (Müll. Arg.) Hemsl.

Agradecimientos. Quiero agradecer a los herbarios G, IAN, NY y P por el préstamo de especímenes y por permitirme el acceso a sus colecciones históricas. Asimismo, deseo reconocer el apoyo del proyecto de la Flora Mesoamericana para la revisión de material en el Missouri Botanical Garden (MO).

Literatura CitADA

Hansen, B. \& R. Wunderlin. 1986. Pentalinon 
Voigt, an earlier name for Urechites Müll. Arg. (Apocynaceae). Taxon 35: 166-168.

Müller, J. 1860. Species novae nonnullae americanae ex ordine Apocynearum et observationes quaedam in species generis Echites auctorum earumque dis- tributio in genera emendata et nova. Linnaea 30: 387-454.

Woodson, R.E. 1936. Studies in the Apocynaceae. IV. The American genera of Echitoideae. Ann. Missouri Bot. Gard. 23: 169-438. 